Hanssen für das Laktophenin besehrieben hat. Bei ciner täglielıen Dosis von 2 bis $3 \mathrm{~g}$ traten nach 10- bis 16 tägiger Darreielıung von Phenokoll unter Mattigkeit, Frösteln und Kopfschmerzen Fieber und Gelbsucht auf. Letztere, von mittlerer Intensität, hielt 14 Tage bis $3 W_{\text {ochen }}$ an und verschwand auch in einem dieser Fälle, in dem das Phenokoll trotz aufgetretenem Iktcrus weitergegeben wurde, ebenso rasch wic in den anderen drei Fällen. In zwei Füllen traten vorübergehend Spuren von Eiweiß im Urin auf. Herpes labialis, den $\mathrm{Hanssen}$ dreimal beim Laktopheninikterus beobaclitetc, habe ieh nicht gesehen.

Aber die weiteren Eigentümlichkeiten, die Hanssen voln Laktopheninikterus berichtet, konnte ich aueh beim Phenokollikterus feststellen.

Zunäehst fiel mir auf, daß nur afebrile Patienten erkrankten, und zwar nur in einem verhältnismäßig geringen Prozentsatz.

In Fällen von lochfieberndem akuten Gelenkrheumatismus trat selbst naeh langem Gebrauehe keine Gelbsueht auf, auch bei Kindern nicht. Ueberlaupt seheint das Alter von 20 bis $60 \mathrm{~J}$ ahren bevorzugt zu sein.

Analog das Laktophenin. Trotz ausgedelnnter Anwendung des Iaktophenins beim Typhus ist das Auftreten von Ikterus hicrbei nieht beobachtet worden (Hanssen, Seifert) (2).

Auch Giftfestigung trat nach Phenokoll wic nach dem Laktophenin ein. Drei der Patienten konnten næeh überstandenem Ikterus das Phenokoll weiternehmen, ohne einen Rüekfall zu bekommen; dem vierten wurde, wie oben erwähnt, trotz eingetretenem Ikterus das Plienokoll weitergegeben, ohne daß Dauer und Grad der Gelbsuclit dadureh verlängert und versehlimmert wurden.

Es treten also nach einer Dosis von 30 bis $40 \mathrm{~g}$ Phenokoll ebenso, wie es Hanssen beim Laktophenin beselırieben lat, bei einem beachtenswerten Prozentsatz von Patienten Krankheitserscheinungen auf, die ganz den Charakter einer Infektionskrankheit tragen. Am meisten kommen sie der Weilsehen Krankheit gleich.

Wie bei dieser Krankheit, bei der der Prozentsatz der Frkrankenden unter vielen unter gleichen Bedingungen Lebenden, z. B. Soldaten im Schützengraben, relativ gering ist, reagiert auch nur eine Minderlıeit der mit Laktophenin und Phenokoll Behandelten.

Nach einer Latenzzeit von mutmaßlich 6 Tagen beim Weil, von 9 bis 10 Tagen beim Laktophenin, von 10 bis 16 Tagen beim Phenokoll tritt unter Frösteln oder Schüttelfrost die hepatisehe Reaktion ein. Auffallenderweise ergeben die Weil-Fülle im Anfange während des hohen Fiebers oft eine positive Diazoreaktion; solange Laktophenin gegeben wird, ist auch beim Laktopheninikterus die Diazoprobe positiv.

Selbst Eiweiß zeigte sieh beim Laktophenin- wie beim Phenokollikterus in Spuren im Urin, und dreimal trat, wie bereits erwähnt, der beim Weil so häufige Herpes labialis beim Laktopheninikterus auf.

Wir stehen also der Tatsache gegenüber, daß zwei ihrer Konstitution naeh genau bekannte, synthetiseh darstellbare Körper im mensehlichen Organismus dieselben Krankheitserseheinungen hervorrufen wie das Findringen der die Weilsche Krankheit verursachenden Spirochäte. Das legt die Vermutung nahe, daß das Spiroehätengift in enger Beziehung zu diesen Benzolderivaten steht und $\mathrm{da} B$ man von den Benzolkörpern aus vielleicht $\mathrm{zu}$ der Konstitution des Spiroehätengiftes gelangen kann.

Das zu erforschen, wird eine verdienstvolle Aufgabe für dic Therapie der Infektionskrankheiten sein, zu der meine Zeilen nur anregen sollen.

L i te r a tu r: 1. Der Laktopheninlkterus, Christiania 1914. - 2. Die Nebenwirkungen der modernen Arzneimittel, Würzburg 1916

\title{
Die Weilsche Krankheit und der Ikterus nach Paraphenetidinen.
}

Von Dr. G. Stalling (Oldenburg), z. Z. im Felde.

Im Jahre 1895 machte Strauss als der Erste auf das Auftreten voll Ikterus nael Darreiclung von Laktophenin aufmerksam, und bald naeh ihm teilten Wenzel, Förster, Kölble und Witthauer ebensolche Beobachtungen mit.

1904 betonte Laaehe neben der relativen Häufigkeit des Laktopheninikterus noeh gewisse Eigentümlichkeiten, vor allem das Auftreten von Ficber und den Eintritt der Gelbsueht nach $27 \mathrm{~g}$.

$1914 \mathrm{kam} \mathrm{Hanssen}(1)$, gestützt auf ein großes Material, in einer ausführlichen Arbeit in seinen Sehlußbetrachtungen zu dem äußerst interessanten Resultat, da $B$ man beim Laktopheninikterus zum ersten Male einer Intoxikation gegenüberstehe, die, wie eine Infektionskrankheit, nit Inkubationszeit, febrilem Stadium und Giftfestigung verläuft und wo die causa noeens ein Benzolderivat, ein wirklicher "Seitenketten". Körper ist.

Jedoch nicht allein das Laktophenin besitzt solehe eigentümliehe Eigensehaften. In den beiden letzten Jahren vor Kriegsausbrueh habe ieh das Phenokoll, das Glykokollphenetidin, mit gutem Erfolge bei rlieu. matischen Erkrankungen angewandt und nach seiner Verabreichung in vier Fällen das Auftreten derselben Erscheinungen beobachtet, die 